\title{
Ağrı ilinde hububat alanlarında zararlı süne, Eurygaster integriceps Puton (Hemiptera: Scutelleridae) ve yumurta parazitoiti Trissolcus grandis (Thomson 1861) (Hymenoptera: Scelionidae)'in yayılış alanları
}

\section{Distribution areas of harmful Eurygaster integriceps Puton (Hemiptera: Scutelleridae) and its' egg parasitoid Trissolcus grandis (Thomson 1861) (Hymenoptera: Scelionidae) in cereal fields in Ağrı}

\author{
İsmail ALASERHAT ${ }^{1 *}$ iD , Adnan CANBAY ${ }^{2}$ iD \\ ${ }^{1}$ Bahçe Kültürleri Araştırma Enstitüsü Müdürlüğü, 24060, Erzincan \\ ${ }^{2}$ Kayısı Araştırma Enstitüsü Müdürlüğü, 44090, Malatya
}

To cite this article:

Alaserhat, i. \& Canbay, A., (2018). Ağrı ilinde hububat alanlarında zararlı süne, Eurygaster integriceps Puton (Hemiptera: Scutelleridae) ve yumurta parazitoiti Trissolcus grandis (Thomson 1861) (Hymenoptera: Scelionidae)'in yayılış alanları. Harran Tarım ve Gıda Bilimleri Dergisi, 22(3): 413-419.

DOI: 10.29050/harranziraat.4049 89

Address for Correspondence: İsmail ALASERHAT

e-mail:

i_alaserhat36@hotmail.com

\section{Received Date:}

13.03.2018

Accepted Date:

11.07.2018

(C) Copyright 2018 by Harran University Faculty of Agriculture. Available on-line at www.dergipark.gov.tr/harranziraat

\section{öz}

Bu çalışma, Ağrı ili hububat alanlarında zararlı Süne, Eurygaster spp. (Hemiptera: Scutelleridae) ile yumurta parazitoitlerinin tespiti ve yayılış alanlarının belirlenmesi amacıyla 2012-2014 yılarında yürütülmüştür. Süne türleri ve parazitoitlerinin belirlenmesi amacıyla hububat ekili alanlardan ergin dönemdeki süne erginleri ve bunlara ait yumurta paketlerinden örnekler alınarak kültüre alınmıştır. Sürveyler hububatın vejetasyon dönemi boyunca (Mayıs-Temmuz) 15-30 gün aralıklarla yapılmıştır. Çalışma sonucunda hububat alanlarında sadece E. integriceps Puton 1881 türü belirlenirken bu türün yumurta parazitoiti olarak da Trissolcus grandis (Thomson 1861) (Hymenoptera: Scelionidae) türü belirlenmiştir. Her iki türün il genelindeki yayılış alanları çalışma sonucunda tespit edilmiştir. Elde edilen sonuçlara göre Ağrı ili Merkez ilçede 21, Eleşkirt ilçesinde 6 köyün süne ile bulaşık olduğu ve yıllara göre Merkez'de 2012 yılında 8, 2013 yılında 9, 2014 yılında 15 köyde; Eleşkirt'te 2012 yılında 2, 2013 yılında 4, 2014 yılında 6 köyde süne popülasyonunun EZE (Ekonomik zarar eşiği)'yi aştığı belirlenmiştir. Ayrıca yumurta parazitoiti T. grandis'in Ağrı ili Merkez ilçede 10, Eleşkirt ilçesinde 4 köyde yayılış gösterdiği tespit edilmiştir. Süne popülasyonunu azaltmada $T$. grandis popülasyonunun korunması önemli rol oynayacaktır.

Anahtar Kelimeler: Eurygaster integriceps, Trissolcus grandis, Süne, Hububat, Ağrı

\section{ABSTRACT}

This study was conducted to determine in 2012-2014, Eurygaster species which are harmful in cereal fields of Ağrı province and its' egg parasitoid and distribution area. In order to determine Eurygaster species and its' parasitoid, adult Eurygaster samples and parasitoid samples determined in cereal fields were taken and cultured. Surveys 
were carried out at intervals of 15-30 days throughout the vegetation period of the cereal. As a result of the study, only E. integriceps Puton 1881 species and Trissolcus grandis (Thomson 1861) (Hymenoptera: Scelionidae) which is egg parasitoids of this species were determined in cereal fields. The distribution areas in the province of both species were determined in the study results. According to the obtained results, it was determined 21 villages of Central district of Ağrı province and 6 villages of Eleşkirt district was contaminated with Sunn pest. It was found that the population of E. integriceps had exceeded EZE (Economic damage threshold), according to the years 8 villages in 2012, 9 villages in 2013, 15 villages in 2014 in Central district of Ağrı province and 2 villages in 2012, 4 villages in 2013, 6 villages in 2014 in Eleşkirt district. It was also found that $T$. grandis which is egg parasitoids of $E$. integriceps distributed in 10 villages in Central district of Ağrı province and 4 villages in Eleşkirt province. The protection of the $T$. grandis population will play an important role in reducing the Sunn pest population.

Key Words: Eurygaster integriceps, Trissolcus grandis, Sunn pest, Cereal, Ağrı

\section{Giriş}

Hububat, insan beslenmesinde temel besin maddelerinden birisi olup, insanoğlu için vazgeçilmez bir gıda maddesidir. Ülkemiz, $\% 1,16$ 'lık hububat üretim payı ile Dünya'da on sekizinci ve $\% 1,6^{\prime}$ lık üretim alanı ile on üçüncü sırada bulunmaktadır (FAO, 2014). Ağrı ili, toplam 1.500 .885 da alanda 239.854 ton hububat üretimli ile ülke ekonomisine katkıda bulunmaktadır (TÜiK, 2016).

İnsan beslenmesinde vazgeçilmez bir kaynak olan tahılda üretimi sınırlayan etmenlerden birisi de böceklerdir. Söz konusu böceklerden Süne [Eurygaster spp. (Hem.: Scutelleridae)] ülkemizde tahılın en önemli zararlısı konumundadır (Lodos 1961; Kılıç ve ark. 1973; Dörtbudak 1979; Memişoğlu 1985; Koçak ve Kılınçer, 2001; Özkan ve Babaroğlu 2015). Türkiye hububat alanlarında ekonomik öneme sahip üç süne türü bulunmaktadır. Bu türler Eurygaster integriceps, E. maura ve E. austriaca'dır. Bu türlerden Marmara Bölgesinde (Edirne, Kırklareli, Çanakkale, Balıkesir, Bursa, Kocaeli ve Sakarya) E. integriceps \% 75, E. austriaca \% 21,1 ve E. maura \% 3,9; Ege Bölgesinde (Manisa, Aydın, Denizli, Muğla ve Uşak) $E$. maura $\% 71,2$, E. austriaca $\% 28,7$ ve $E$. integriceps \% 0,1; Akdeniz bölgesinde (Antalya, Burdur, Adana ve Mersin) E. integriceps \% 50, E. maura \% 38,8 ve $E$. austriaca \% 11,2; iç Anadolu Bölgesinde (Ankara, Konya, Kırşehir ve Yozgat) E. maura \% 98,4 ve E. austriaca \% 1,6; Doğu Anadolu Bölgesinde (Elazığ, Van, Ağrı ve Iğdır) $E$. integriceps \% 72,4, E. maura \% 25 ve $E$. austriaca \% 2,6 ve Güneydoğu Anadolu Bölgesinde (Diyarbakır, Şanlıurfa, Mardin ve Gaziantep) ise E. integriceps \% 100 bulunmaktadırlar (Koçak ve ark., 2014).

Ağrı ilinde sünenin bazı yıllar lokal olsa da epidemi yapması, süne türleri ve doğal düşman popülasyonunun bilinmemesi gibi nedenler bu konunun çalışııması gerekliğini ortaya çıkarmıştır.

Bu çalışmada Ağrı ili hububat alanlarında bulunan süne (Eurygaster) türü (Hemiptera: Scutelleridae) ve yumurta parazitoitinin, yayılış alanlarının belirlenmesi amaçlanmıştır. Çalışma sonucunda Ağrı ilinde hâkim olan süne (Eurygaster) (Hemiptera: Scutelleridae) ve yumurta parazitoiti (Trissolcus) (Hymenoptera: Scelionidae) türü ve bu türlerin il genelindeki yayılış alanları tespit edilmiştir.

\section{Materyal ve Yöntem}

\section{Materyal}

Çalışmanın ana materyalini; Ağrı ili hububat ekim alanları (buğday ve arpa), süne 
erginleri, süne yumurta paketleri ve yumurta parazitoiti oluşturmuştur. Ayrıca $50 \times 50 \mathrm{~cm}$ boyutundaki demir çerçeve, kültür kafesleri ve çeşitli laboratuvar malzemeleri vs. çalışmada kullanılmıştır.

\section{Metot}

Ağrı ilindeki Süne türlerini belirlemek amacıyla örneklemeler Mayıs ayının ilk haftasından Temmuz ayının son haftasına kadar olan dönemde 15-30 gün aralıklarla araziye gidilerek gerçekleştirilmiştir. Ağrı iı Gıda, Tarım ve Hayvancılık Müdürlüğü teknik elemanları ile birlikte yapılan sürveylerde, sünenin kışlamış ergin ve yumurta paketi örnekleri elle toplanarak örneklemeler yapılmıştır. Kışlamış erginlerde kıymetlendirme sürveyi yaparak nimf mücadelesi yapılması muhtemel alanlar belirlenmiştir. Örnekleme yapılan hububat tarlalarında gerçekleştirilen sayım adedi tarla büyüklüğüne göre aşağıda verilmiştir (Anonim, 2008).

$\begin{array}{lll}1-15 & \text { dekar tarlada } & 8-12 \text { sayım } \\ 16-50 & \text { dekar tarlada } & 12-16 \text { sayım } \\ 51-200 & \text { dekar tarlada } & 16-24 \text { sayım } \\ 201-800 & \text { dekar tarlada } & 24-32 \text { sayım } \\ >800 & \text { dekar tarlada } & 32-40 \text { sayım }\end{array}$

Hububat ekili tarlalardan toplanan kışlamış süne erginleri, gerekli etiket bilgileri kaydedildikten sonra petri kaplarına konularak laboratuvara getirilmiştir. Arazi sürveyleri esnasında belirlenen ve yumurta renkleri filizi yeşilden ziyade koyu renge kararmış süne yumurta paketleri laboratuvara getirilerek parazitoit çıkışları için petri kaplarında oda koşullarında kültüre alınmıştır. Kültüre alınan bu örnekler günlük olarak kontrol edilmiş ve yumurtalardan çıkış yapan parazitoit bireyler içerisinde \% 70 etil alkol bulunan ephendorf tüplere alınarak teşhise hazır hale getirilmiştir. Elde edilen süne ve yumurta parazitoiti örneklerin teşhisleri Sayın Prof. Dr. Erhan KOÇAK (Süleyman Demirel Üniversitesi, Ziraat Fakültesi, Tarımsal Biyoteknoloji Bölümü) tarafından yapılmıştır. Belirlenen süne ve yumurta parazitoiti türler kayıt altına alınarak il genelindeki yayılış alanları tespit edilmiştir.

\section{Araştırma Bulguları ve Tartışma}

Ağrı ili Merkez ve Eleşkirt ilçesine bağlı toplam 27 köydeki hububat ekim alanlarından 582 adet kışlamış süne ergini toplanmış ve yapılan teşhis sonucu sadece Eurygaster integriceps Puton 1881 (Hemiptera: Scutelleridae) türü tespit edilmiştir. Bu türün il genelindeki yayıııs alanları ve ekonomik zarar eşiğini aşan alanlar Çizelge $1^{\prime}$ de verilmiştir. Dünya'da Eurygaster cinsine bağlı 15 türün bulunduğu, ülkemizde ise bu cinse giren 7 türün saptandığı ve bunlardan en önemlilerinin E. integriceps, E. maura (Avrupa sünesi) ve $E$. austriaca (Yassı vücutlu süne) olduğu ifade edilmiştir (Anonim 2008). Koçak ve ark. (2014), Türkiye hububat alanlarındaki Süne (Eurygaster spp.) türlerinin dağılımı üzerine yürüttükleri çalışmada ekonomik öneme sahip $E$. integriceps, $E$. maura ve $E$. austriaca olmak üzere üç süne türü bulunduğunu belirlemişlerdir. Bu türlerin sırası ile Marmara Bölgesinde (Edirne, Kırklareli, Çanakkale, Balıkesir, Bursa, Kocaeli ve Sakarya) $E$. integriceps, $E$. austriaca ve $E$. maura; Ege Bölgesinde (Manisa, Aydın, Denizli, Muğla ve Uşak) E. maura, E. austriaca ve E. integriceps; Akdeniz bölgesinde (Antalya, Burdur, Adana ve Mersin) E. integriceps, E.maura ve E. austriaca; iç Anadolu Bölgesinde (Ankara, Konya, Kırşehir ve Yozgat) E. maura ve E. austriaca; Doğu Anadolu Bölgesinde (Elazığ, Van, Ağrı ve Iğdır) $E$. integriceps $E$. maura ve $E$. austriaca ve 
Güneydoğu Anadolu Bölgesinde (Diyarbakır, Şanlıurfa, Mardin ve Gaziantep) ise E. integriceps'in daha yoğun ve yaygın olarak bulunduklarını tespit etmişlerdir. Salis et al. (2010), Eurygaster cinsine bağlı olan sünelerin dünyada Avrupa'dan tutun Asya ve Kuzey Afrika'ya kadar olan çok geniş bir alanda yayılış gösterdiğini ifade etmişlerdir. Çalışma sonucunda Ağrı ilinde sadece $E$. integriceps türü belirlenirken, bizimde çalışma alanımız olan Ağrı ilini içerisine alan Doğu Anadolu Bölgesinde (Elazığ, Van, Ağrı ve Iğdır illeri) yürütülen bir diğer çalışmada $E$. integriceps, E. maura ve E. austriaca türlerinin tespit edildiği belirtilmiştir (Koçak ve ark., 2014).

Çizelge 1. Ağrı ilinde sürvey yapılan hububat alanlarında 2012-2014 yılında saptanan Eurygaster integriceps Puton 1881 ve yayılış alanları

Table 1. Eurygaster integriceps Puton 1881, determined in cereal fields in Ağrı province in 2012-2014 and its' distribution areas

\begin{tabular}{|c|c|c|c|c|}
\hline \multicolumn{2}{|c|}{ Yayılış alanları } & 2012 & 2013 & 2014 \\
\hline \multirow{21}{*}{ 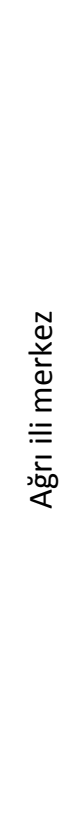 } & Ahmetbey & & + & \\
\hline & Akbulgur & & & + \\
\hline & Anakaya & & + & \\
\hline & Arakonak & & & + \\
\hline & Aşağı Yoldüzü & & & + \\
\hline & Aşkale & + & + & \\
\hline & Baloluk & + & & \\
\hline & Çamurlu & + & + & + \\
\hline & Eliaçık & + & + & + \\
\hline & Karasu & & + & \\
\hline & Kayabey & & & + \\
\hline & Murathan & + & & + \\
\hline & Otlubayır & & & + \\
\hline & Ozanlar & + & + & + \\
\hline & Tezeren & & + & + \\
\hline & Yazıcı & + & & \\
\hline & Yazılı & + & & + \\
\hline & Yığıntepe & & & + \\
\hline & Yoncalı & & & + \\
\hline & Yukarı Yoldüzü & & & + \\
\hline & Yurtpınar & & + & + \\
\hline \multirow{6}{*}{ 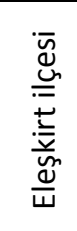 } & Goncalı & & + & + \\
\hline & Haydaroğlu & & & + \\
\hline & İkizgeçe & & + & + \\
\hline & Mollasüleyman & + & & + \\
\hline & Toprakkale & + & + & + \\
\hline & Yanıkdere & & + & + \\
\hline
\end{tabular}

Eurygaster integriceps Ağrı ili merkez ve Eleşkirt ilçesine bağlı Çizelge 1'de verilen tüm köylerde her üç yılda belirlenmiştir. Ancak nimf sürveyleri sonucu ekonomik zarar eşiğini aşan alanlar (+) ile işaretlenmiştir. Ekonomik zarar eşiği $\geq 10$ adet $\mathrm{nimf} / \mathrm{m}^{2}$ olarak baz alınmıştır (Anonim, 2008; Anonim, 2016).

Ağrı ili Merkez ve Eleşkirt ilçesine bağlı toplam 14 köyden, 48 adet parazitlenmiş Süne yumurta paketlerinden toplam 106 adet yumurta parazitoiti elde edilmiştir. Elde edilen parazitoitlerden yapılan teşhis sonucunda sadece Trissolcus grandis (Thomson 1861) (Hymenoptera: Scelionidae) türü tespit edilmiştir. Bu türün il genelindeki yayılış alanları Çizelge 2'de verilmiştir.

Çizelge 2. Ağrı ilinde sürvey yapılan hububat alanlarında 2012-2014 yılında saptanan Trissolcus grandis (Thomson 1861) ve yayılış alanları

Table 2. Trissolcus grandis (Thomson 1861), determined in cereal fields in Ağrı province in 2012-2014 and its' distribution areas

\begin{tabular}{|c|c|c|c|c|}
\hline Yayılıs & anları & 2012 & 2013 & 2014 \\
\hline & Ahmetbey & & & \\
\hline & Akbulgur & & & \\
\hline & Anakaya & & & \\
\hline & Arakonak & & & \\
\hline & Aşağı Yoldüzü & & & + \\
\hline & Aşkale & + & + & \\
\hline & Baloluk & & & \\
\hline & Çamurlu & & + & + \\
\hline$\underset{\mathscr{Q}}{\underline{y}}$ & Eliaçık & + & + & + \\
\hline$\frac{\vdots}{d}$ & Karasu & & & \\
\hline. & Kayabey & & & \\
\hline 竧 & Murathan & & & + \\
\hline 昰 & Otlubayır & & & \\
\hline & Ozanlar & & + & + \\
\hline & Tezeren & & & \\
\hline & Yazıcı & + & & \\
\hline & Yazılı & & & + \\
\hline & Yığıntepe & & & \\
\hline & Yoncalı & & & \\
\hline & Yukarı Yoldüzü & & & + \\
\hline & Yurtpınar & & + & \\
\hline & Goncalı & & + & + \\
\hline 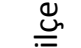 & Haydaroğlu & & & \\
\hline $\bar{E}$ & İkizgeçe & & + & + \\
\hline 咅 & Mollasüleyman & & & \\
\hline$\frac{9}{14}$ & Toprakkale & & + & \\
\hline & Yanıkdere & & + & + \\
\hline
\end{tabular}


Çizelge 2 incelendiğinde yumurta parazitoiti olan T. grandis'in Ağrı iline bağlı Aşağı Yoldüzü, Aşkale, Çamurlu, Eliaçık, Murathan, Ozanlar, Yazıcı, Yazılı, Yukarı Yoldüzü ve Yurtpınar köylerinde; Eleşkirt ilçesine bağlı Goncalı, Ikizgeçe, Toprakkale ve Yanıkdere köylerinde yayılış gösterdiği görülmektedir. Scelionidae (Hymenoptera) familyasına giren parazitoitlerin Eurygaster spp.'nin yumurta parazitoitleri oldukları; Tachinidae (Diptera) familyasına giren parazitoitlerin ise sünenin nimf ve ergin parazitoiti oldukları ifade edilmektedir (Waage, 1998; Gözüaçık ve ark., 2010; Samin et al., 2010). Bunlardan Trissolcus (Scelionidae) türlerinin E. integriceps'nin önemli yumurta parazitoitlerinden olduğu belirtilmektedir (Gözüaçık and Yiğit, 2016). T. anitus, T. basalis, T. choaspes, $T$. culturatus, $T$. festivae, $T$. grandis, T. histani, T. rufiventris, $T$. pseudoturesis, $T$. rungsi, $T$. reticulatus, $T$. scutellaris, $T$. semistriatus, $T$. simoni ve $T$. vassilievi türlerinin Türkiye'de süne türlerinin yumurta parazitoitleri oldukları ifade edilmektedir (Brown, 1962; Yüksel, 1968; Kılıç et al., 1980; Dikyar, 1981; Şimşek ve Sezer, 1985; Akıncı ve Soysal, 1992; Melan, 1994; Memişoğlu ve Özer, 1994; Şimşek ve ark., 1994; Öncüer ve Kıvan, 1995; Kodan ve Gürkan, 2000; Koçak ve Kılınçer, 2002; Gözüaçık ve Yiğit, 2012).

Tarla ve Doğanlar (1999), Hatay ilindeki hububat alanlarında yürütmüş oldukları çalışma sonucunda $E$. integriceps'in Scelionidae familyasına bağlı 7 ve Encyrtidae familyasına bağı 2 tür olmak üzere toplam 9 yumurta parazitoit türünü tespit etmişlerdir. $\mathrm{Bu}$ türlerin Trissolcus semistriatus Ness, $T$. festivae Viktorov, T. pseudoturesis Rjach., T. rufiventris Mayr, Telenomus chloropus Thom., T. basalis Woll., T. simoni Mayr, Ooencyrtus telenomicidae Vass. ve Ooencyrtus sp. olduğunu belirtmişledir. Kodan ve Gürkan (2000), T. grandis'in $-18^{\circ} \mathrm{C}^{\prime}$ de 8 ay depolanan Dolycoris baccarum L. yumurtalarında \%50'nin üzerinde parazitlenme ve ergin çıkışı olduğunu ve depolama süreleri arttıkça dişi çıkışı azaldığını ve parazitoitlerin gelişme sürelerinin uzadığını saptamışlardır. Koçak ve Kılınçer (2001), Türkiye hububat alanlarının en önemli zararlısı olan süne türleri (Eurygaster spp.) üzerinde 8 Trissolcus türü (T. grandis Thomson, $T$. rufiventris, $T$. pseudoturesis Rjachovsky, $T$. semistriatus, $T$. simoni (Mayr), T. vassilievi (Mayr), $T$. djadetshko Rjachovsky ve T. manteroi Kieffer) tespit etmişlerdir. Aynı çalışmada Türkiye genelinde $T$. semistriatus'un dominant tür olduğu ve bu türü sırasıyla $T$. simoni, $T$. grandis, T. vassilievi, T. pseudoturesis, $T$. rufiventris, $T$. djadetshko ve $T$. manteroi türlerinin izlediği ve süne popülasyonunu baskı altına almada $T$. semistriatus, $T$. grandis, T. simoni, T. vassilievi'nin önemli olduğunu, $T$. semistriatus ve $T$. grandis'in coğrafik olarak bütün bölgelerde bulunduğunu belirtmişlerdir.

\section{Sonuçlar}

Çalışma sonucunda Ağrı ili Merkez ilçede 21, Eleşkirt ilçesinde 6 köyün süne ile bulaşık olduğu ve yıllara göre Merkez'de 2012 yılında 8, 2013 yılında 9, 2014 yılında 15 köyde; Eleşkirt'te 2012 yılında 2, 2013 yılında 4, 2014 yılında 6 köyde süne popülasyonunun EZE (Ekonomik zarar eşiği)'yi aştığı belirlenmiştir.

Yumurta parazitoiti tür olan Trissolcus grandis'in Ağrı ili hububat alanlarında yaygın olması biyolojik mücadele açısından önemli ve çalışılması gereken bir konudur. Ayrıca yapılan bu araştırma sonucunda doğal düşmanların korunması, barınması, beslenmesi, kimyasal ilaçlardan uzak 
durulması koşulu ile doğal düşmanların alternatif mücadele olarak kolaylıkla önerilebileceğini, tamamlayıcı metotlarla, Entegre Zararlı Yönetimi (IPM) çerçevesinde daha da verimli ve etkili bir mücadelenin yapılabileceği düşünülmektedir.

\section{Ekler}

Çalışma sonucunda elde edilen Süne, Eurygaster integriceps ve yumurta parazitoiti olan Trissolcus grandis'in teşhislerini yapan Sayın Prof. Dr. Erhan KOÇAK (Süleyman Demirel Üniversitesi, Ziraat Fakültesi, Tarımsal Biyoteknoloji Bölümü)'a teşekkür ederiz. Ayrıca sürveyler esnasında bize yardımlarını esirgemeyen Sayın Ziraat Mühendisi Vedat ASLAN ve Sayın emekli Ziraat Teknisyeni Cemal ARSLAN (Ağrı ili Gıda, Tarım ve Hayvancılık Müdürlüğü, Bitkisel Üretim ve Bitki Sağlığı Şubesi)'a teşekkürü bir borç biliriz.

\section{Kaynaklar}

Akıncı, A.R. Soysal, A., 1992. Trakya bölgesinde süne (Eurygaster spp.)'nin yumurta parazitoitleri ve etkinlikleri üzerinde araştırmalar. Uluslararası Entegre Zirai Mücadele Sempozyumu (15-17 Ekim 1992, İzmir) Bildirileri, 258s.

Anonim, 2008. Zirai mücadele teknik talimatları. T.C. Gıda, Tarım ve Hayvancılık Bakanlığı, Tarımsal Araştırmalar ve Politikalar Genel Müdürlüğü, Cilt:1, 283 s., Ankara.

Anonim, 2016. Hububat Hastalık ve Zararlıları ile Mücadele. T.C. Gıda, Tarım ve Hayvancilık Bakanlığı, Gıda ve Kontrol Genel Müdürlüğü, 1$45 \mathrm{~s}$, Ankara.

Brown, E.S., 1962. Notes on parasites of Pentatomidae and Scutelleridae (Hemiptera) in Middle East Countries, with observations on biological control. Bulletin of Entomology Research, 53: 241-256.

Dörtbudak Y., Koyuncu, N., 1979. Orta Anadolu'da Süne (Eurygaster spp.) türleri ve yoğunlukları üzerinde ön çalışmalar. Zirai Mücadele Araştırma Yıllığı, 2-3.

Dikyar, R., 1981. Biology and control of Aelia rostrata in cental Anatolia. Bulletin Organisation Europeenne et Mediterraneenne pour la Protection des plantes, 11 (2): 39-41.

FAO, 2014. Statistical data of FAO. http://www.fao.org/faostat/en/\#data/QC

Access date: 21.03.2017

Gözüaçık, C., Kara, K., Karaca, V., Duman, M., Mutlu, Ç., Melan, K., 2010. Güneydoğu Anadolu Bölgesi'nde Süne, Eurygaster integriceps Put. (Hem.: Scutelleridae)'nin ergin parazitoitleri ve etkinlikleri. Harran Üniversitesi Ziraat Fakültesi Dergisi, 14 (1): 1-8.

Gözüaçık, C., Yiğit, A., 2012. Süne, Eurygaster integriceps Puton (Hemiptera: Scutelleridae) yumurta parazitoiti, Trissolcus semistriatus Nees (Hymenoptera: Scelionidae)'un konukçu tercihleri. Türkiye Biyolojik Mücadele Dergisi, 3 (2): 145-156.

Gözüaçık, C., Yiğit, A., 2016. The alternative hosts of Trissolcus species, egg parasitoids of sunn pest and host-parazitoid interactions in South Eastern Anatolia Region, Turkey. Journal of Agricultural, Food and Environmental Sciences, 67: 68-74.

Kılıç A. U., Çatalpınar A., Adıgüzel N., Dörtbudak Y., Çavdaroğlu S., 1973. Güneydoğu Anadolu Bölgesinde Süne (Eurygaster integriceps Put.)' nin yayılışı, biyolojisi, ekolojisi, epidemiolojisi ile daha uygun kimyevi mücadele yöntemlerinin araştırılması. A- 106.602 no'lu proje nihai rapor. $121 \mathrm{~s}$.

Kılı̧̧, A.U., Çatalpınar, A., Adıgüzel, N., 1980. Güneydoğu Anadolu Bölgesi'nde Süne (Eurygaster integriceps Put.) üzerinde entegre mücadele imkanlarının araştırılması. Diyarbakır Bölge Zirai Mücadele Araştırma Enstitüsü Yayınları, $14 \mathrm{~s}$.

Koçak, E., Kılınçer, N., 2001. Türkiye Süne [Eurygaster spp. (Hem.: Scutelleridae)] yumurta parazitoidi Trissolcus (Hym.:Scelionidae) türleri. Bitki Koruma Bülteni, 41 (3-4): 167-181.

Koçak, E., Kılınçer, N., 2002. The taxonomy and morphology of Trissolcus spp. (Hymenoptera: Scelionidae) parasitoids on the eggs of Sunn pest (Eurygaster spp., Scutelleridae, Hemiptera), across Turkey. Eggs Parasitoids 6th International Symposium, (15-18 September, Perugia, Italy), p 38.

Koçak, E., Bilginturan, S., Kaya, E., Gözüaçık, C., Babaroğlu, N. İslamoğlu, M., Çetin, G., Tülek, A., 2014. Türkiye hububat alanlarındaki süne (Eurygaster spp.) türlerinin dağııımı, $115 \mathrm{~s}$. Türkiye V. Bitki Koruma Kongresi (3-5 Şubat 2014, Antalya) Bildirileri, $399 \mathrm{~s}$.

Kodan, M., Gürkan, M.O., 2000. Dondurulmuş Dolycoris baccarum L. (Hemiptera: Pentatomidae) yumurtalarında Trissolcus 
grandis Thomson (Hymenoptera:

Scelionidae)'in gelişmesi, 305-315 s. Türkiye IV. Entomoloji Kongresi (12-15 Eylül 2000, Aydın) $569 \mathrm{~s}$.

Lodos, N., 1961. Türkiye, Irak, İran ve Suriye'de Süne (Eurygaster integriceps Put.) Problemi Üzerinde Incelemeler. Ege Üniversitesi Ziraat Fakültesi Yayınları, No: 51, İzmir, $115 \mathrm{s.}$

Melan, K., 1994. Trakya bölgesinde süne türleri ve süne yumurta parazitoitleri, 147-154 s. Türkiye III. Biyolojik Mücadele Kongresi (25-28 Ocak 1994, ìzmir).

Memişoğlu H. 1985. Ankara ilinde Süne Türlerinin (Eurygaster spp.) (Hemiptera: Pentatomidae) Yayılışları ve E. maura L.'nin Biyo-Ekolojisi ile Savaş Yöntemleri Üzerinde Araştırmalar. Ankara Üniversitesi Fen Bilimleri Enstitüsü Bitki Koruma Anabilim Dalı, (Basılmamış) Doktora Tezi, Ankara, $194 \mathrm{~s}$.

Memişoğlu, H., Özer, M., 1994. Ankara ilinde Avrupa sünesi (Eurygaster maura L., (Hemiptera: Scutelleridae)'nin doğal düşmanları ve etkinlikleri, 175-186 s. Türkiye III. Biyolojik Mücadele Kongresi (25-28 Ocak 1994, İzmir).

Öncüer, C., Kıvan, M., 1995. Tekirdağ ve çevresinde Eurygaster (Het.: Scutelleridae) türleri, tanımları, yayılışları ve bunlardan Eurygaster integriceps Put.'in biyolojisi ve doğal düşmanları üzerinde araştırmalar. Türkiye Tarım ve Orman Dergisi, 19 (4): 223- 230.

Özkan M., Babaroğlu N.E., 2015. Süne. Gıda ve Kontrol Genel Müdürlüğü Yayınları, Ses Reklam İletişim ve Basım Hizmetleri, Ankara, $208 \mathrm{~s}$.

Salis, L., Goula, M., Valero, J., Gordún, E. 2010. Prolamin proteins alteration in durum wheat by species of the genus Eurygaster and Aelia (Insecta, Hemiptera). Spanish Journal of Agricultural Research, 8(1): 82-90.

Samin, N., Shojal, M., Asgari, S., Ghahari, H., Koçak, E., 2010. Sunn pest (Eurygaster integriceps Puton,
Hemiptera: Scutelleridae) and its Scelionid (Hymenoptera: Scelionidae) and Tachinid (Diptera: Tachinidae) parasitoids in Iran. Linzer Biol. Beitr., 42 (2): 1421-1435.

Şimşek, N., Sezer A.C., 1985. Hatay ilinde buğdayda Süne (Eurygaster integriceps Put.)'nin yumurta ve nimf popülasyonu ile zararı üzerinde ön çalışmalar. Bitki Koruma Bülteni, 25 (1-2): 3048.

Şimşek, Z., Yılmaz, T., Yaşarakıncı, N., 1994. Güneydoğu Anadolu bölgesinde süne (Eurygaster integriceps Put.) ile yumurta parazitoiti (Trissolcus semistriatus Nees)'nin populasyon gelişmeleri üzerinde araştırmalar, 165-175 s. Türkiye III. Biyolojik Mücadele Kongresi (25- 28 Ocak 1994, İzmir).

Tarla, Ş., Doğanlar, M. 1999. Hatay ilinde süne, Eurygaster integriceps Put. (Hemiptera: Scutelleridae) yumurta parazitoitleri, bunlara alternatif konukçu olan pentatomid türleri ve bu türlerin konukçu bitkileri, 97-106 s. Türkiye IV. Biyolojik Mücadele Kongresi (26-29 Ocak, Adana), $633 \mathrm{~s}$.

TÜiK, 2016. Türkiye İstatistik Kurumu verileri. http://rapory.tuik.gov.tr/21-03-2017-10:11:5216704249092073753848729461131.html?

Erişim tarihi: 21.03.2017

Waage, J.K., 1998. Prospects for augmentation of egg parasitoids for management of sunn pest, Eurygaster integriceps and related species. Integrated Sunn Pest Control. Ankara Plant Protection Central Research Institute (6-9 January 1998, Ankara).

Yüksel, M. 1968. Güney \& Güneydoğu Anadolu'da süne (Eurygaster integriceps Put.)'nin yayılışı, biyolojisi, ekolojisi, epidemiyolojisi ve zararı üzerinde araştırmalar. T.C. Tarım Bakanlığı, Zirai Mücadele ve Zirai Karantina Genel Müdürlüğü Yayınları No: 46, Teknik Bülten, Ankara, 255 s. 